$£ 120000$ to $£ 210000$ depending on the type of polysomnography requested. With nearly $50 \%$ patients managed with oximetry it would cost $£ 68400$ to $£ 113000$ leading to huge cost saving without compromising on the quality of service.

Conclusion Judicious use of oximetry can help deliver cost effective sleep service.

\section{Improving delivery of care in cystic fibrosis P234 THE IMPORTANCE OF APPROPRIATE REFERENCE EOUATIONS FOR SPIROMETRY: LESSONS LEARNED FROM THE CYSTIC FIBROSIS GENE THERAPY "RUN-IN" STUDY}

doi:10.1136/thoraxjnl-2011-201054c.234

${ }^{1} \mathrm{G}$ Davies, ${ }^{1} \mathrm{~A} J$ Simpson, ${ }^{1} \mathrm{~K}$ J Bayfield, ${ }^{2} \mathrm{M} J \mathrm{McGovern},{ }^{2} \mathrm{M}$ A Embley, ${ }^{2} \mathrm{H}$ S Sheridan, ${ }^{1} \mathrm{C}$ Saunders, ${ }^{2} \mathrm{M}$ H Dewar, ${ }^{2} \mathrm{~S}$ Cunningham, ${ }^{3} \mathrm{E}$ W F W Alton, ${ }^{2} \mathrm{~J}$ A Innes, ${ }^{1} \mathrm{~J} \mathrm{C}$ Davies. ${ }^{1}$ Imperial College, London, UK; ${ }^{2}$ University of Edinburgh, Edinburgh, UK; ${ }^{3} U K$ Cystic Fibrosis Gene Therapy Consortium, London, UK

Introduction and Objectives The "Run-In" study is an on-going longitudinal, observational study of CF patients assessing outcome measures for a future gene therapy trial. Spirometry is performed at each visit and volumes are converted to \% predicted values according to published reference equations; historically these were separate for adults and children. Here, we describe the issues arising from this approach, and highlight the benefit of using a reference source which bridges the transition from child to adulthood.

Methods CF subjects (=10 years; $\mathrm{FEV}_{1}=40 \%$ predicted) were recruited from three sites in London and Edinburgh. Visits were undertaken during periods of stability every $3-6$ months; data presented here are from the first four visits. Spirometry was performed on an Easyone spirometer. Volumes were converted to \% predicted values according to Rosenthal ( $<18$ years) and Quanjer (=18 years) reference equations. The $\mathrm{FEV}_{1}$ raw data were subsequently re-analysed using Stanojevic reference equations, which span all age ranges. Comparisons were made using paired t-tests.

Results 191 patients attended visit 1 (mean age 22.7 years, $55 \%$ male; 91 patients <18 years). Rosenthal and Quanjer $\mathrm{FEV}_{1} \%$ predicted values were significantly higher than the Stanojevic values: mean differences 2.8 (95\% CI 1.9 to 3.7) for children with Rosenthal equations $(p<0.0001)$, and 2.4 (95\% CI 2.1 to 2.8$)$ for adults using Quanjer equations ( $p<0.0001) .10$ patients transitioned between paediatric and adult reference ranges during the study period; the slope of change in their $\mathrm{FEV}_{1} \%$ over visits $1-4$ was significantly greater with Rosenthal/Quanjer references than with Stanojevic $(p=0.001)$ largely due to an artefactual drop when switching from Rosenthal to Quanjer values. As an example, a female patient aged 17.8 years at visit 1 had a drop in absolute $\mathrm{FEV}_{1} \%$ predicted between visits 1 and 2 of $11 \%$ when Rosenthal/ Quanjer were used but only 3\% with Stanojevic reference values.

Conclusions Our results highlight issues raised when separate adult and paediatric spirometry reference ranges are used in longitudinal study. The UK CF Gene Therapy Consortium has adopted the Stanojevic reference source for all spirometry analysis in its ongoing Clinical Programme.

Funding UK CF Trust.

\section{P235 \\ A UK REGISTRY STUDY OF PROPHYLACTIC ANTIBIOTIC USE FOR STAPHYLOCOCCUS AUREUS IN CHILDREN WITH CYSTIC FIBROSIS}

doi:10.1136/thoraxjnl-2011-201054c.235

D K H Lo, M H Hurley, A Prayle, A R Smyth. University of Nottingham, Nottingham, UK

Background The UK antibiotic guidelines for cystic fibrosis (CF) recommend that all infants should be prescribed a prophylactic narrow spectrum antibiotic, such as flucloxacillin, from diagnosis until 3 years of age. We wished to evaluate the prevalence of prophylactic antibiotic use in the UK and the effect this had on the microbiological outcome of children with CF.

Methods A registry search was conducted on the UK CF registry to include all children $<3$ years at the time of the 2009 dataset (UK CF registry. Cystic Fibrosis Trust, 2011). Information on antibiotic prophylaxis ("chronicoral antibiotic not prescribed to treat an exacerbation") and bacterial status (no growth, intermittent or chronic) are entered at the time of annual assessment and refer to the previous year.

Results We identified 609 children who were born between August 2006 and December 2009, for whom data were available. Of these, 480 children (78.8\%) were on prophylaxis and, 385 (80.2\%) were on flucloxacillin alone. Prevalence of chronic/intermittent Staphylococcus aureus and Pseudomonas aeruginosa were similar between those not on antibiotics to those on flucloxacillin only. The use of "other" antibiotics was significantly associated with an increased prevalence of $P$ aeruginosa ( $p=0.005$, Bonferroni corrected threshold $=0.0125$ ).

Conclusions Despite current recommendations a sizeable minority of children with CF are not on anti-Staphylococcal prophylaxis. Of those who are, the majority receive flucloxacillin. Given the limited dataset, we did not detect any significant differences in microbiological outcome between those on regular Flucloxacillin to those on no antibiotics. Of note, the prevalence of $S$ aureus in the under three group is around 7\% compared with the overall UK prevalence of $15.2 \%$. Prophylactic use of antibiotics other than Flucloxacillin (mostly cephalosporins; $\mathrm{n}=36$ out of 95) appear associated with increased prevalence of $P$ aeruginos $a$. This is consistent with findings from a previous US study implicating cephalosporin prophylaxis in acquisition of infection with $P$ aeruginosa $(J$ Pediatr 2002;140:299-305). Randomised controlled trials with long term follow-up, using clinically relevant outcomes, are warranted in order to better understand the effect antistaphylococcal prophylaxis has on the progression of CF lung disease.

\section{Abstract P235 Table 1}

\begin{tabular}{|c|c|c|c|c|}
\hline & $\begin{array}{l}\text { Not on } \\
\text { antibiotics }\end{array}$ & $\begin{array}{l}\text { On regular } \\
\text { flucloxacillin }\end{array}$ & $\begin{array}{l}\text { On other (inc. } \\
\text { combinations) }\end{array}$ & Total \\
\hline $\begin{array}{l}\text { Chronic/intermittent } \\
S \text { aureus positive }\end{array}$ & $10(7.75 \%)$ & $29(7.53 \%)$ & $5(5.26 \%)$ & 44 \\
\hline $\begin{array}{l}\text { Chronic/intermittent } \\
P \text { aeruginosa positive }\end{array}$ & $20(15.50 \%)$ & $61(15.84 \%)$ & $31(32.63 \%)$ & 112 \\
\hline $\begin{array}{l}\text { Chronic/intermittent } S \text { aureus } \\
\text { and } P \text { aeruginosa positive }\end{array}$ & $6(4.65 \%)$ & $23(5.97 \%)$ & $3(3.16 \%)$ & 32 \\
\hline No positive cultures & $93(72.09 \%)$ & $272(70.65 \%)$ & $56(58.95 \%)$ & 421 \\
\hline Total & 129 & 385 & 95 & 609 \\
\hline
\end{tabular}

\section{P236 CYSTIC FIBROSIS DEATHS IN USA AND UK: COMPARISONS OF REGISTRY AND ROUTINE DATA}

doi:10.1136/thoraxjnl-2011-201054c.236

${ }^{1} \mathrm{~F}$ Chowdhury, ${ }^{1} \mathrm{M} \mathrm{J}$ Wildman, ${ }^{2} \mathrm{E}$ Gunn, ${ }^{3} \mathrm{D}$ Bilton. ${ }^{1}$ Adult Cystic Fibrosis Centre, Northern General Hospital, Sheffield, UK; ${ }^{2}$ Cystic Fibrosis Trust, Bromley, Kent, UK; ${ }^{3}$ Royal Brompton Hospital, London, UK

Background MDT care in dedicated centres has been a contributor to improved Cystic Fibrosis (CF) survival and in UK and USA outcomes for patients in centres, and is collected by national CF registries. Routine national death data using ICD-10 codes will identify all CF deaths giving an indication of how many deaths occur in patients not receiving centre care. It might be suspected that the UK health service with universal access might have a 